\title{
A COMPLEXA RELAÇÃO ENTRE MODERNIDADE E CAPITALISMO: UMA VISÃO DESCOLONIAL ${ }^{1}$
}

\author{
The Complex Relationship between Modernity and Capitalism: a \\ Decolonial Vision
}

\author{
Ramón GROSFOGUEL \\ Universidade da Califórnia, Berkeley \\ grosfogu@berkeley.edu \\ Gabriel ONESKO \\ Universidade Federal do Paraná \\ gabrielonesko@gmail.com \\ https://orcid.org/0000-0002-4705-110X
}

\begin{abstract}
RESUMO: Este ensaio trata da relação histórica entre modernidade e capitalismo, assim como das possibilidades para um horizonte de transformação que supere as tradicionais concepções binárias de ver e estar no mundo. Ao contrário do que expõe a esquerda ocidentalizada, propõe-se aqui uma visão crítica decolonial dessa relação. A partir da presente intervenção teórica, discutem-se as consequências políticas de ver a modernidade como um projeto civilizatório ou entendê-la como uma possiblidade entre outras. Por meio dele, portanto, pretendemos estudar de que modo e sob quais categorias conceituamos a relação entre modernidade e capitalismo, um assunto chave para o debate político contemporâneo. Pretendemos pensar em um projeto "transmoderno" que reconheça o colonialismo em sua dimensão subjetiva como requisito para um verdadeiro projeto de descolonização. PALAVRAS-CHAVE: Capitalismo; Colonialidade; Modernidade; Patriarcado; Racismo.
\end{abstract}

ABSTRACT: This essay addresses the historical relationship between modernity and capitalism as well as the options of a horizon of transformation that goes beyond the traditional binary conceptions of seeing and being in the world. Contrary to what a Westernised left declares, it is proposed a decolonial critical vision of this relationship. From this

1 Publicação original: GROSFOGUEL, Ramón. La compleja relación entre modernidad y capitalismo: una visión descolonial. Pléyade, v.21, 2018, p.29-47.

Esse artigo é uma versão melhorada e estendida da conferência "La compleja relación entre modernidad y capitalismo", proferida pelo autor na Universidade Nacional Autônoma do México em outubro de 2017, durante o II Colóquio De Lo pós-colonial a la descolonización. Genealogías, debate, evaluación y crítica en América Latina. 
theoretical intervention, we discuss the political consequences of considering modernity as a civilizing project or to understand it as a possible project among others. We therefore propose to study how and under what categories we conceptualize the relationship between modernity and capitalism, a key issue for contemporary political debates. We propose to think of a "transmodern" project that recognizes colonialism in its subjective dimension as a prerequisite for a true decolonizing project. KEYWORDS: Capitalism; Coloniality; Modernity; Patriarchy; Racism.

Vou começar com uma ideia que já repeti em outros lugares, mas que eu gosto de enfatizar para o caso de haver pessoas que não saibam. "Modernidade-Colonialidade" não é um grupo, é uma rede, nunca foi um grupo, e digo isso como um membro fundador e organizador de muitas conferências e colóquios que se tornaram referências dessa rede. Posso assegurar que sempre foi uma rede de composição heterogênea e com muitas diferenças internas. Nunca houve uma comunidade como tal, porque sempre houve divergências. Discrepâncias que, de qualquer forma, foram as que finalmente dotaram a rede de certa criatividade e imaginação, pois cada integrante contribuía com ideias e problemáticas diversas. Não obstante, construíram-se muitos mitos sobre "ModernidadeColonialidade", tal como essa tendência errônea em pensar que essa rede foi um grupo de pesquisa interdisciplinar que se reunia com frequência para debater ideias políticas para a transformação social do Sul global. Não se trata disso - considero necessário esclarecer esse ponto, porque, em parte, os responsáveis por causar essa confusão somos nós, ao usar a palavra "grupo" com uma leviandade desmedida - de uma maneira bastante informal, "ontologizando" seu significado como se fosse uma coletividade acordada a partir de uma afinidade teórica e prática profunda que, de fato, não funciona dessa maneira. Podese pensar, então, que talvez a palavra "grupo" foi usada de maneira descuidada, sem a justiça que demanda o uso da linguagem, pois exterioriza para a sociedade a imagem de um grupo de pesquisadores que está organizado em função de interesses compartilhados, e isso jamais aconteceu - creio que hoje essas discrepâncias são mais evidentes do que nunca - há diferenças políticas de base, como acontece, por exemplo, a respeito da situação sociopolítica venezuelana. Como se sabe, há um setor da rede "ModernidadeColonialidade", pesquisadores muito proeminentes no campo das humanidades e das ciências sociais, que assinaram um documento terrível, um documento que repete as mesmas 
teses da oposição neoliberal de direita na Venezuela. ${ }^{2}$ Nele, assinaram, lamentavelmente, pessoas com as quais eu e muita gente ficamos surpresos. Desde muito tempo eu vinha anunciando publicamente algumas críticas à rede, perguntando-me, acima de tudo, como é que em seu interior reproduziam-se certas práticas coloniais contra as quais, supõese, estava chamada a combater - para mim, por exemplo, é fundamental reconhecer de onde os pesquisadores retiram suas ideias. Considero inaceitável que os autores da colonialidade bebam de fontes bibliográficas - tais como o pensamento indígena latinoamericano, afro-latino-americano, etc. - e sequer referenciem esses autores. Não se trata de uma questão acadêmica, como qual método de citação seguir; trata-se de uma questão de "justiça cognitiva" . É problemático, do meu ponto de vista, que a rede "ModernidadeColonialidade" construa seu corpus teórico apropriando-se e ignorando, no plano epistemológico, tradições de pensamento historicamente inferiorizadas e invisibilizadas. É o que se denomina "extrativismo epistêmico".

A rede "Modernidade-Colonialidade" tem um problema ético e político. Muitos confundiram a minha crítica como se eu estivesse em uma cruzada pessoal contra Aníbal Quijano ou Walter Mignolo. Eu não tenho nada pessoal contra eles; pelo contrário, tratase de uma crítica às suas práticas ético-políticas. Do ponto de vista político, parece-me extremamente problemático que continuem reproduzindo práticas coloniais, e de uma forma mais perversa, porque agora o fazem em nome do pensamento decolonial. Essas críticas que fiz foram julgadas como um ataque pessoal no momento, como se eu tivesse a pretensão de estar no centro da discussão para converter-me no líder da decolonialidade, assunto que, insisto, não me interessa. Para mim o problema é ético-político: como estamos nos relacionando com outras genealogias de pensamentos não ocidentais? Como disse em várias entrevistas e artigos, não se pode tomar para si as ideias da tradição do pensamento radical negro e indígena sem citar nenhum de seus autores, tal como Quijano

\footnotetext{
${ }^{2}$ QUIJANO, Aníbal et al. "Lllamado internacional urgente a detener la escalada de violência en Venezuela. Mirar a Venezuela, más allá de la polarización” (2017). Disponível em: http:// llamadointernacionalvenezuela.blogspot.de/2017/05/llamado-internacional-urgente-detener_30. $\mathrm{html}$. Acesso em: $5 \mathrm{dez}$. 2017. Esse documento, que repete as teses da esquerda neoliberal e próimperial na Venezuela, foi respondido por outro, assinado por muitas pessoas e idealizado por mim, intitulado "La izquierda despolarizada: Del monólogo de Próspero al Diálogo con Calibán", disponível em: https://drive.google.com/file/d/0B6g8xuEX_KoJZ0R3bzdMb0NINUk/view. Acesso em: jun. 2018.

${ }^{3}$ Para o conceito de "justiça cognitiva" consulte-se: GROSFOGUEL, Ramón. "Los dilemas de los estudios étnicos estadounidenses: multiculturalismo identitario, colonización disciplinaria y epistemologías decoloniales" (Universitas Humanística 63, 2007) e SANTOS, Boaventura de Sousa. Democracia de alta intensidad: apuntes para democratizar la democracia (La Paz: Unidad de Análisis e Investigación del Área de Educación, 2004).
} 
faz constantemente ${ }^{4}$. O extrativismo e o racismo epistêmico devem ser erradicados das práticas da produção de conhecimento e constitui-se uma grande contradição quando são realizados em nome do decolonial - cabe não seguir reproduzindo os padrões culturais dominantes da colonialidade do poder e do saber ${ }^{5}$, e esta é uma tarefa urgente.

Outro tema que me parece crucial é o que ocorreu a respeito do debate político sobre a Venezuela. Como disse acima, uma parte significativa da rede "ModernidadeColonialidade" aderiu sem ressalvas a um documento bastante problemático, e como resposta a isso, preparamos um texto junto com outros colegas e figuras sociais. Esse último foi assinado por muitas pessoas da Venezuela, o que é curioso, porque no outro documento que citei, todos os assinantes não eram venezuelanos, ou os venezuelanos que assinaram não participaram do projeto bolivariano, sendo pessoas que necessariamente haviam deixado o país. A questão, então, é se o "giro decolonial" deve supor como primeiro passo um compromisso político explícito com os movimentos sociais e os movimentos anti-imperialistas. Em outras palavras, afirmo que não podemos produzir pensamento decolonial sem pensar junto aos/e com os movimentos sociais, do contrário, nos transformamos em antropólogos e deixamos de fazer decolonialidade. Em segundo lugar, o decolonial também pressupõe assumir uma perspectiva crítica, anti-imperialista e anticolonialista. Embora nem todo anti-imperialismo e anticolonialismo sejam em si mesmos decoloniais, toda abordagem decolonial, pelo contrário, deve ser anti-imperialista e anticolonial. Se não for assim, de que colonialidade estamos falando?

Eu venho de um Departamento de Estudos Étnicos da Universidade da Califórnia, em Berkeley, que foi produto de uma longa greve de estudantes. Esse departamento foi formado através de um protesto massivo protagonizado por estudantes racializados dentro do império norte-americano. Foi uma grande mobilização de estudantes negros, latinos, asiáticos e indígenas estadunidenses em 1969. Logo houve outra greve em 1999 que, entre outras coisas, buscou conquistar novos espaços de trabalho que não se renovavam há mais de trinta anos. Na prática isso significava que, quando um professor morria ou se retirava da Universidade, sua vaga não era renovada. Em trinta anos o departamento ia desaparecer, motivo que gerou outra greve em 1999, e desde então estamos em luta. Essa greve, além de gerar novas vagas para professores, originou o Centro de Estudos de Raça e Gênero da Universidade da Califórnia em Berkeley. Gosto de ressaltar esse ponto para

\footnotetext{
${ }^{4}$ Leia-se minha crítica a Mignolo e Quijano em: GROSFOGUEL, Ramón. "Del 'extractivismo económico' al 'extractivismo epistémico' y 'extractivismo ontológico': una forma destructiva de conocer, ser y estar en el mundo”. Tábula Rasa 4, 2016.

5 GROSFOGUEL, Ramón. "Del extractivismo económico al extractivismo epistémico y ontológico". Revista Internacional de Comunicación y Desarrollo 4, 2015.
}

Revista X, v. 16, n. 1, p. 6-23, 2021. 
aqueles que reproduzem o mito de que Berkeley é uma Universidade de prestígio aberta em que se pode fazer de tudo. Porque não, esse departamento não foi um presente, foi o resultado de luta, suor e sangue contra o império. Por isso, não é crível pensar que um dia os brancos liberais despertaram pela manhã e disseram: "agora vamos fazer justiça cognitiva e vamos deixar que esses 'negrinhos' e 'latinozinhos' entrem e tenham seu espaço na Universidade". Não foi assim. Foi uma greve sangrenta. A greve de 1969 foi a mais duradoura em toda a história dos Estados Unidos: durou nove meses. E, por isso, o Estado não mobilizou a polícia do campus, nem a polícia da cidade, mobilizou a Guarda Nacional da Califórnia para reprimir os estudantes que demandavam legitimamente um espaço de pensamento próprio dentro de uma Universidade branca-ocidental. Digo tudo isso para que entendam mais ou menos de onde falo. Sendo assim, talvez eu entre em contradição com outros projetos, como o chamado "Modernidade-Colonialidade", que são projetos de sentido acadêmico. Porém, para mim, a decolonialidade não é uma opção. Para mim a decolonialidade é uma necessidade política urgente. E não é urgente somente em um nível individual, mas também coletivo. A seguir, explicarei meu posicionamento a partir da relação entre capitalismo e modernidade.

Esclarecidos os pontos anteriores, gostaria de adentrar na discussão sobre o capitalismo e sua relação com a modernidade. No seio dessa problemática se disputa boa parte do debate político contemporâneo. O projeto da modernidade, tal como é concebido pelas perspectivas do Norte global ou eurocêntricas do Sul, se pensa a partir de uma dimensão fundamentalmente geográfica, é visto como uma "geopolítica do conhecimento" 6 que não reflete o suficiente acerca das posições estruturais de poder que o capitalismo globalizado impõe. É importante esclarecer esse assunto, externando a ideia geográfica, pois caso contrário, ingressamos em um labirinto cheio de problemas que, digamos assim, precipita toda uma soma de reducionismos ingênuos, mas com consequências políticas enormes. É nesse sentido que caminha a crítica pública que fiz a Walter Mignolo. Ele tende a pensar que, se um sujeito vem da Europa, já não pode produzir pensamento decolonial e, viceversa, se alguém vem do continente americano é automaticamente colonial por definição - porém, eu discordo dessa aproximação. Isso é mais complicado, porque segundo essa teoria não é possível explicar as expressões contemporâneas da colonialidade, colapsando

\footnotetext{
${ }^{6}$ MIGNOLO, Walter. Capitalismo y geopolítica del conocimiento: el eurocentrismo y la filosofía de la liberación en el debate intelectual contemporáneo. Buenos Aires: Ediciones del Signo, 2014. Revista X, v. 16, n. 1, p. 6-23, 2021. 
de maneira artificial a posição epistêmica com a posição social, ou pior ainda, com a posição geográfica. É importante recordar que o êxito da ordem social capitalista tem se dado pelo fato de os que estão abaixo pensarem epistemicamente como os que estão acima. Sendo assim, em termos conceituais é complexo discutir a relação modernidadecapitalismo partindo de uma perspectiva essencialista que reduz as tensões históricoestruturais a uma reflexão estritamente geográfica. Nem sempre a posição social coincide com a posição epistêmica. Ou não era para esta defasagem que o conceito de "hegemonia" de Gramsci apontava? De um ponto de vista marxista, Gramsci falava da ideologia e, no contexto decolonial, falamos de epistemologia. Porém, o ponto que diz respeito de como a posição social não coincide com a posição epistêmica se mantém. O ocidentalocentrismo faz com que sujeitos colonizados pensem epistemicamente como os colonizadores.

Este tipo de aproximação teórica reducionista nos moldes de Mignolo é desastrosa politicamente falando, pois induz à confusão de amigos com inimigos através do seguinte procedimento: se quem fala é um branco europeu-ocidental-metropolitano, você assume ontologicamente que é seu inimigo. E também ao contrário, se é um negro ou indígena do continente americano, é ontologicamente seu aliado. Entretanto, cuidado: primeiro devese conferir onde estão situados epistêmica e politicamente os sujeitos. Consideremos isso antes de julgar com tanta facilidade a partir da cor da pele ou procedência. Com isso, não estou negando o conceito de "geopolítica do conhecimento", o que acontece é que esses conceitos devem ser analisados partindo de um ponto de vista filosófico e não de um reducionismo geográfico. De qualquer maneira, chamo a atenção sobre todas essas coisas porque são partes da situação complexa que eu considero que existe hoje na rede "Modernidade-Colonialidade". E, claro, outra complicação está no âmbito político que pretende pensar se o "Modernidade-Colonialidade" é um projeto político necessário ou uma opção epistemológica relacionada aos interesses e conjunturas acadêmicas do momento. Há uma diferença, de fato, entre nós, que vemos essa rede como um projeto político necessário e aqueles que a veem como um projeto puramente acadêmico.

A relação entre modernidade e capitalismo é um dos principais temas de nossos tempos. Como e segundo quais categorias conceituamos a relação entre modernidade e capitalismo é um assunto chave para o debate político contemporâneo. A questão central é a maneira de pensar, ser e estar no mundo. Partindo de uma visão eurocêntrica, a modernidade surge como um projeto emancipatório, mas por quê? Vejamos. Se remontarmos ao século XVI e observarmos a emergência do sistema-mundo, veremos que no interior dos centros metropolitanos existe toda uma crítica feita por sujeitos que foram dominados, explorados e oprimidos e que reclamam seus direitos de cidadãos, de 
redistribuição da riqueza, de igualdade, etc.; é uma crítica, digamos assim, da Europa para a Europa. Ao mesmo tempo, existem críticas que são feitas a esses centros metropolitanos que partem de fora, das margens, da periferia, dos povos colonizados. Temos aqui, então, dois pontos de vista da modernidade como processo civilizatório que em si mesmo realiza um recorte fortemente ocidentalocêntrico do mundo. Assim, o local de onde observamos o mundo, vai definir como avaliamos o projeto de modernidade. Para explicar isso vou utilizar uma metáfora proveniente da democracia ateniense.

Como é sabido, os indivíduos livres viviam dentro da polis graças à servidão dos escravos que habitavam fora dos muros. A Grécia antiga era parte de outro sistemamundo, com lógicas civilizatórias diferentes. Do meu ponto de vista, a expansão do sistema-mundo moderno capitalista não é diferente da democracia ateniense, mas em escala global. Dentro dos muros tem-se, em termos metafóricos e a modo de exemplo, 15 a $20 \%$ da população do mundo, e fora deles uns 80 ou $85 \%$. O problema é o seguinte. Há uma crítica de parte da esquerda ocidentalizada que, repito, recusa-se em pensar a posição epistêmica de onde se pensam as relações de poder. É uma esquerda que aparece no ocidente, mas também na periferia colonizada e que se propaga em distintos continentes como uma esquerda ocidentalizada. Ocorre com a esquerda ocidentalizada o mesmo que acontece com a universidade ocidentalizada, que está em todas as partes. Há, então, uma crítica interna que se faz a partir do próprio projeto moderno. É uma crítica que procura melhorar a situação dos oprimidos dentro dos muros, sem questionar a ordem social dominante, sem questionar as próprias muralhas e as opressões que vivem os que estão fora delas. Há uma série de revoluções que valem de referências universais para o pensamento eurocêntrico de esquerda como a revolução inglesa ao final do século XVII, ou a revolução francesa ou a revolução estadunidense ao final do século XVIII. De fato, delas derivam as principais categorias políticas com as quais o pensamento ocidentalocêntrico vai operar sua filosofia. Como podemos ver, essa crítica se centra nos processos de transformação social dos sujeitos subalternos, mas sempre referindo-se aos subalternos que lutam de dentro dos muros. O problema, em minha opinião, emerge quando essas revoluções ou críticas radicais não levam em conta a importância de derrubar as muralhas, mas constituem um questionamento crítico que deixa as muralhas intactas, ou melhor dizendo, a ordem imperialista global. Creio que aí temos a construção de uma esquerda, mas uma esquerda imperialista colonial, pois constrói um projeto político no qual tudo o que reivindica é melhorar a situação dentro das muralhas, sem questioná-las e sem problematizar a dominação que esse sistema-mundo exerce sobre os habitantes de fora delas - ao não disputar esse espaço, essa esquerda corrompe-se, convertendo-se 
em uma esquerda que pode ter as críticas mais bonitas do mundo, mas que no fundo está apenas reivindicando uma melhor posição entre os saques das periferias do mundo, e sem questionar esses saques - não questionam as estruturas de poder que produzem o saque e o empobrecimento de uma imensa maioria da população mundial que reside justamente fora das muralhas e que é submetida às formas mais despóticas, paupérrimas e violentas de acumulação de capital. As reivindicações dessa esquerda ocidentalizada traduzemse basicamente em demandar mais liberdade, mais direitos, melhorias salariais e mais recursos materiais para os oprimidos dentro das muralhas, mas sem questionar as colunas do sistema que permitem a escravização, dominação, colonização e o despotismo da acumulação de capital nas periferias do mundo. Essa é uma esquerda, em síntese, que acaba corrompendo-se porque torna-se cúmplice do projeto civilizatório moderno-colonial.

Do ponto de vista da Europa, o que surge a partir de sua expansão colonial é uma nova configuração para a acumulação do capital. O que passa a existir é a exploração econômica como um problema que a humanidade enfrenta. Por outro lado, com a expansão territorial europeia camuflam-se lógicas de dominação que formam parte da dinâmica civilizatória da modernidade, lógicas que são estruturantes e constitutivas do capitalismo histórico ${ }^{7}$. Analisando a expansão da Europa, tive debates com Immanuel Wallerstein e Giovanni Arrighi ${ }^{8}$ quando fui professor na Universidade de Binghamton, e em várias ocasiões perguntei para eles: Por que vocês insistem em dizer que as estruturas do sistema-mundo são fundamentalmente uma divisão internacional do trabalho e um sistema interestatal de centros, periferias e semiperiferias articuladas entre si para a acumulação global do capital? Todo o resto pertenceria à superestrutura, ou seja, o racismo, o sexismo, o cristianismo e o patriarcado. Eles me responderam que o ponto central no sistema-mundo, a inovação que houve com a colonização europeia a partir de 1492, é a nova lógica de acumulação do capital, e, portanto, um novo sistema econômico. Então eu disse a eles, mas por que vocês não consideram como parte das estruturas de dominação do sistema-mundo, a dominação patriarcal, a dominação epistemológica, o racismo ou a dominação de como se pensa a relação dos humanos com outras formas de vida não humanas? Ao que me disseram: o que acontece Ramón, é que isso não é novo, tudo isso que você mencionou já estava na Europa - o patriarcado, o cristianismo, o racismo. Seguindo esse argumento, consequentemente, o relevante do sistema-mundo capitalista

\footnotetext{
${ }^{7}$ WALLERSTEIN, Immanuel. El capitalismo histórico. Madrid: Siglo Veintiuno editores, 2003. 8 WALLERSTEIN, Immanuel; ARRIGHI, Giovanni; K. HOPKINS, Terence. Movimientos antisistémicos. Madrid: Ediciones Akal, 1999.
} 
formado com a expansão colonial europeia a partir de 1492 seria a configuração de uma nova economia em escala mundial, cuja nova lógica é a acumulação incessante de capital.

Um dos problemas desse raciocínio é que a história local da Europa é tida como história mundial. No entanto, se mudamos o ponto de partida, aparecem outras lógicas de dominação, que não existiam antes da colonização europeia, e que eram completamente novas na América, Ásia e outras partes do mundo. O cristianismo não existia, o racismo não existia, em muitos lugares nem se quer existia a dominação patriarcal de caráter cristocêntrico, porque o que se globaliza é o patriarcado cristão. Por isso, em muitas regiões, como em povos da África e das Américas, o patriarcado não existia antes da chegada dos conquistadores. Recentemente, foi publicada na Colômbia uma tradução do livro de Oyèrónké Oyèwumí, La Invención de las Mujeres, um excelente texto que apresenta de forma concreta como o patriarcado não existia no norte da África antes da colonização europeia ${ }^{9}$. Oyèrónké é uma companheira iorubá que escreve esse livro documentando o que ocorreu na Nigéria e na África Ocidental. Inclusive é um trabalho citado por María Lugones, mas que não havia sido publicado em castelhano até agora.

O ponto é, pois, que se analisarmos o sistema-mundo capitalista, alterando a geografia da razão podemos observar toda uma carga de múltiplas hierarquias com suas respectivas práticas de dominação, que são novas para o resto do mundo, mas que, talvez, já estivessem presentes na história local europeia. Porém, para a história local de outras partes do mundo, como em Abya-Yala, estas pautas de sujeição política e exploração econômica são verdadeiramente novidade. Se esses padrões são novos em outras partes do mundo, devemos incorporá-los à trama de dominação que constrói o sistema-mundo, ao invés de deixá-los como uma dimensão secundária que resulta da acumulação do capital ou como superestrutura. Isso quer dizer que não existe "o capitalismo": o que há é o capitalismo realmente existente. Um capitalismo histórico que, lembremo-nos, está organizado a partir das lógicas civilizatórias da modernidade. Não podemos reduzir o capitalismo como infraestrutura e a modernidade como superestrutura, ou seja, dizer que a modernidade é um simples epifenômeno do fator econômico. Com efeito, tampouco podemos pensar a modernidade totalmente autônoma e separada do capitalismo. Pelo contrário, o capitalismo histórico, o capitalismo realmente existente, é o sistema econômico da modernidade.

O capitalismo que mencionei acima está estruturado, organizado e constituído desde o seu interior pelas lógicas civilizatórias da modernidade. Se o capitalismo é genocida,

\footnotetext{
${ }^{9}$ Ver OYÈWÙMÍ, Oyèrónké. La invención de las mujeres. Una pespectiva africana sobre los discursos occidentales de género. Bogotá: Ediciones en la frontera, 2017.
}

Revista X, v. 16, n. 1, p. 6-23, 2021. 
epistemicida, ecologicida, racista, cristocêntrico, eurocêntrico, sexista, destruidor de comunidades, do mundo agrário e do campesinato, é porque está alinhado essencialmente às lógicas civilizatórias da modernidade. $\mathrm{O}$ capitalismo sempre foi colonial, de modo que sua projeção histórica não é possível sem a expansão colonial. Podemos discutir abstratamente o que haveria sido do capitalismo se tivesse adotado lógicas civilizatórias distintas. Todavia, o problema não é como haveria sido, se não, como é. Lembremo-nos da frase que usava para comentar o socialismo no século XX, o "socialismo realmente existente", não aquele que imaginamos. Utilizo essa frase para pensar o capitalismo hoje. Portanto, se pensamos a modernidade desde a perspectiva dos sujeitos que estão dentro dos centros de poder, tanto opressores como oprimidos que estão dentro dos muros, a modernidade surge como um projeto emancipatório, pois, partindo do ponto de vista dos oprimidos que estão dentro das muralhas, há uma sensação de que, em termos sociais, políticos, de direitos cidadãos e de recursos materiais, sua situação melhorou. Recordemos que, dentro das lutas travadas no interior desses muros, os setores dominantes fazem concessões aos subalternos que nunca estariam dispostos a fazer aos oprimidos que estão fora deles, e podem fazê-las graças à superexploração que exercem fora das muralhas. É por isso que concedem licenças e direitos para que trabalhadores metropolitanos tenham melhores condições de trabalho, melhores salários, acesso a leis trabalhistas e códigos de regulação. Porém, insisto que o lado de dentro e de fora dos muros não é uma questão geográfica. É uma posicionalidade nas relações de dominação. Enfatizo esse elemento, porque, se olharmos para a modernidade de dentro dos muros, ela surge como um projeto emancipatório, pois representa uma ruptura com o antigo regime, mais bens materiais, maior riqueza, tecnologia, etc. Porém, se avaliarmos a modernidade partindo de fora das muralhas, perceberemos que a colonialidade não foi somente uma expansão econômica, nem somente a expansão da Europa ao resto do mundo, ou a incorporação da mão de obra barata em uma divisão internacional do trabalho de todos os territórios conquistados, não é somente isso: é a destruição de outras formas de organizar a vida. Nesse sentido, a expansão colonial europeia significou a destruição de outras civilizações e a imposição de uma nova civilização que, no início do século XX, já era uma civilização mundial. Nesse processo, a civilização ocidental também foi mudando ao passo da expansão colonial e das diversas transformações do sistema mundial nos últimos cinco séculos.

3

Com tudo o que disse até aqui, podemos ver que as lógicas civilizatórias do capitalismo histórico estão entre as questões mais importantes para pensar a modernidade. 
Tomemos como um exemplo o racismo. Até certo ponto, é problemático compreender o sistema-mundo capitalista, explicar a divisão internacional do trabalho e interpretar os padrões históricos de acumulação do capital sem considerar, a meu ver, que o racismo é um princípio organizador da economia política. O racismo organiza a divisão do trabalho. E essa ideia não é de Aníbal Quijano, é uma tese muito antiga que podemos encontrar nos escritos de Fanon, Robinson e Davis ${ }^{10}$, e em muitos outros autores que provêm do pensamento caribenho, afro-americano e indígena das Américas. Apresentavam a discussão com outros termos, é certo. Alguns falavam de "colonialismo interno" faziam referência ao "capitalismo racial" como Robinson, e outros, ao invés disso, refletiam sobre o fenômeno do racismo enquanto infraestrutura, como Fanon. Deste modo, poderíamos dizer que há uma profunda genealogia de pensamento que precede Quijano. Digo isso para descentralizarmos a ideia de que todas essas problemáticas provêm da rede "Modernidade-Colonialidade", pois não é assim. Essa rede resgata diversas tradições de pensamento, mas lamentavelmente acaba, como havia dito antes, por não reconhecer de onde retira suas premissas epistemológicas, e por isso afirmo que a atitude de Quijano é, para mim, um assunto de injustiça cognitiva.

Os exemplos podem multiplicar-se. Atualmente o capitalismo é um sistema destrutivo da vida, não somente por seu esforço em acumular riqueza, mas também devido à sua cosmologia. Melhor dizendo - não há tecnologia sem cosmologia. Essa ideia de que existe tecnologia neutra é um dos grandes mitos da modernidade. Se partirmos do princípio de que toda tecnologia tem cosmologia, teríamos que nos perguntar, então, qual é a cosmologia do capitalismo histórico. A cosmologia do capitalismo é o dualismo ontológico cartesiano que estabelece o mito de uma separação radical entre "homem" e "natureza", entre "sujeito" e "objeto". Essa é a cosmologia do capitalismo, e implica, entre outras coisas, em inferiorizar outras formas de vida não humanas. Objetifica as outras formas de vida, ou seja, as transforma em objeto para serem destruídas e consumidas como mercadorias. É a alienação da natureza em mercadoria. Essa ferramenta assume de maneira dualista que, como a vida humana é ontologicamente exterior as outras formas de vida, essas últimas podem ser destruídas sem que a vida humana seja afetada. Em outras

\footnotetext{
${ }^{10}$ FANON, Frantz. Os condenados da terra. $2^{\text {a }}$ ed. Rio de Janeiro: Civilização Brasileira, 1979; ROBINSON, Cedric. Black Marxism: The Making of the Black Radical Tradition. Carolina do Norte: University of North Carolina Press, 2000; DAVIS, Angela. Mulheres, raça e classe. Tradução de Heici Regina Candiani. São Paulo: Boitempo, 2016.

${ }^{11}$ GONZÁLEZ, Pablo Casanova. Colonialismo interno (uma redefinição). In: BORON, Atilio; AMADEO, Javier; GONZÁLEZ, Sabrina (Org.) A teoria Marxista hoje. Problemas e perspectivas. 2007. p. 431-458. Disponível em: http://bibliotecavirtual.clacso.org.ar/clacso/formacionvirtual/20100715073000/boron.pdf. Acesso em: 03 mai. 2020.
} 
palavras, qualquer tecnologia proveniente da cosmologia do dualismo cartesiano leva consigo a racionalidade da destruição da vida. Essa cosmologia do dualismo cartesiano foi a chave para a criação de tecnologias no capitalismo concreto durante os últimos quatro séculos, gerando um sistema ecologicida. A modernidade, com sua teologia do progresso, dirá que evoluímos conforme o tempo passa, e tudo o que fica para trás, o que está no passado, transforma-se em algo pior do que o presente. Essa é a lógica moderna. Não me parece prudente idealizar o passado. Pelo contrário, o que se deve fazer é entender os processos sociais, políticos, econômicos e culturais utilizando uma perspectiva histórica de longa duração. Não há dúvida de que nas civilizações não ocidentais havia luzes e sombras, mas não podemos cair nesses preceitos moderno-ocidentais de descartar o que estava no passado e aplaudir tudo o que está no presente, como se fosse a solução. Se analisarmos todas essas civilizações que foram destruídas pelo projeto modernocolonial-capitalista-patriarcal do ocidente, todas, de uma forma ou de outra, foram menos agressivas à vida do que a atual civilização moderna, e o motivo disso é muito simples, pois independentemente dos problemas que podiam ter, nenhuma outra civilização viveu sob uma fórmula cartesiana, todas adotavam uma versão holística nas relações entre vida humana e não humana. De modo que, se você produz uma tecnologia partindo de um princípio holístico, irá buscar a reprodução da vida de forma racional, sem hierarquizá-la como inferior ou superior, mas sim pensando em uma coexistência dentro de um mesmo universo, porque o desbalanceamento dessa ordem cosmogônica implica na destruição da vida. Esse é um princípio elementar de todas as cosmovisões do planeta que você pode encontrar na noção de Pachamama no mundo andino, ou na noção de Ubuntu na África, você pode viajar ao redor do globo e encontrará muitas visões de mundo que são holísticas porque não pensam a relação entre humano e não humano de uma maneira dualista como no ocidente. Por esse simples motivo, essa civilização moderna é a mais agressiva à vida do que todas as existentes até agora.

Essa cosmovisão dualista cartesiana constitui a maneira de produzir tecnologias, por isso afirmo que não existe "o capitalismo" como sistema aliado, mas que há um capitalismo realmente existente, um capitalismo histórico, que é o sistema econômico da civilização moderna. Como já mencionei anteriormente, as lógicas civilizatórias da modernidade constituem o capitalismo histórico. O mesmo vale para o patriarcado, especialmente o de natureza cristocêntrica, que é o que se globaliza. Temos então um sistema capitalista que reproduz lógicas patriarcais centradas no cristianismo. Poderíamos mencionar muitos casos para exemplificar o anterior, e cada exemplo necessitaria de sua própria elaboração. Digo isso para sustentar o fato de que, não podemos continuar 
pensando as relações entre capitalismo e modernidade como duas questões exteriores enquanto tentamos estimular um projeto de esquerda anticapitalista que cumpre as lógicas civilizatórias da modernidade, porque, dessa maneira, repetimos tudo aquilo contra o que estamos lutando. Uma das grandes falhas foi, justamente, colocar o sistema econômico como o x da questão, pensando nele como se fosse um sistema isolado, e pensando no restante simplesmente como superestrutura ou epifenômeno. A premissa era a seguinte: se resolvermos o problema econômico, todo o restante irá se resolver porque, em última instância, o que determina as demais questões é a contradição capital-trabalho, sendo ela a responsável por produzir o racismo, patriarcado, ecologicídio, etc. Então, na experiência socialista do século XX esse projeto fracassa. Em grande parte porque, não somente esses problemas não foram resolvidos, como também não se resolveu o que se pretendia solucionar, que era a contradição capital-trabalho. Haja vista que, se você organiza-se contra o capital e usa meios problemáticos da própria civilização que organiza o capitalismo, os meios que usa vão construir os fins, e terminarão reproduzindo novamente o mesmo sistema. Se nos organizamos contra o capital de maneira racista, eurocêntrica, sexista e dualista cartesiana vamos acabar reproduzindo tudo o que estamos lutando contra e terminaremos (como no socialismo do século XX) construindo um capitalismo de estado.

Esse raciocínio resulta em implicações teóricas importantes, mas também tem implicações políticas. Portanto, cabe perguntar-se, qual é o projeto político? Ou seja, se vamos nos organizar contra esse sistema, qual horizonte político iremos seguir? Iremos simplesmente alterar o sistema econômico deixando intacto todo o resto? Isso não nos levará muito longe, pois seguiremos reproduzindo as lógicas civilizatórias da modernidade que corrompem as lutas contra o capital ou contra qualquer outra demanda social, como a dominação de gênero ou a dominação racial. Se não levarmos em consideração essa crise civilizatória, e pensarmos que se trata somente de uma crise econômica, inevitavelmente iremos reproduzir todas as lógicas de dominação contra as quais estamos lutando. Em suma, se vamos pensar as relações de dominação partindo de um cenário estritamente econômico, como se todo o restante fosse superestrutura, iremos terminar reproduzindo mais uma vez todos os problemas contra os quais supostamente estamos lutando. É por isso que eu os convido a pensar que estamos em uma civilização com um sistema econômico específico, e não em um sistema econômico que produz uma civilização. Isso implica repercussões políticas enormes, porque a transformação social já não pode ser somente anticapitalista - já desconsideramos isso - temos que pensar uma luta antissistêmica contra a modernidade para acabar com o sistema capitalista, e para isso temos que entender do que 
estamos falando: que o capitalismo não é um sistema isolado nem puramente econômico, mas um sistema econômico de uma civilização e, portanto, trata-se de construir uma nova civilização. Quero dizer que quando falamos de capitalismo histórico nos referimos a uma pluralidade de opressões que já estão implantadas nas lógicas civilizatórias da modernidade. Como vocês podem ver, a discussão que estou levantando não é somente teórica já que possui grandes implicações políticas.

Com isso, não estou dizendo que vamos pegar uma lupa e procurar ao redor do mundo movimentos políticos perfeitos, e até que encontremos essa forma de ação coletiva antissistêmica, adotemos a postura de não sujar as mãos com a política, não envolverse com nenhum movimento por nenhum ser perfeito nos transformaria em um tipo de elite que produz uma crítica moral impecável, que está acima de todos, mas que não consegue mudar o mundo. Ao não nos envolvermos politicamente, porque estamos nessa espécie de pedestal esperando o movimento antissistêmico perfeito e criticando todos os movimentos existentes por não se ajustarem a esses pré-requisitos esperados, acabamos em um elitismo ultra radical que é na verdade conservador, porque termina deixando o status quo intacto. Minha proposta é que devemos realizar uma crítica capaz de gerar uma subjetividade "transmoderna" no sentido de Enrique Dussel ${ }^{12}$, ou seja, construir uma subjetividade que rompa com as amarras epistêmicas da modernidade. Para que, junto com isso, possamos entrar em lutas, sejam elas quais forem, com críticas que faremos internamente, apoiando as lutas políticas e sociais para que, a partir delas, possamos nos transformar em um vírus da transmodernidade. Isto é, onde quer que adentremos, promovamos uma subjetividade transmoderna que evolua para uma crítica civilizatória da modernidade, para não reproduzir suas lógicas de dominação.

Considerando esses pontos, emerge a tarefa urgente de propor um novo tipo de subjetividade para, assim, produzir uma política descolonial, pois, caso contrário, reproduzimos as mesmas práticas contra as quais estamos resistindo. Esse é o problema político dessa discussão teórica que tentei desenvolver ao longo desse ensaio. Creio que o principal debate da rede "Modernidade-Colonialidade", que foi por onde iniciei, começa com a relação modernidade e capitalismo que não está tão clara como pensamos, e que, com exceção de alguns autores como Enrique Dussel, Nelson Maldonado-Torres, Franz

\footnotetext{
${ }^{12}$ DUSSEL, Enrique. Posmodernidad y transmodernidad. Puebla: Universidad Iberoamericana Plantel Laguna, 1999.
}

Revista X, v. 16, n. 1, p. 6-23, 2021. 
Hinkelammert ou Juan José Bautista ainda causa uma série de problemas teóricos na academia. Vemos que de alguns pesquisadores da rede parte uma crítica antimoderna radical, mas que não teoriza realmente do que se trata a modernidade nem sua relação com o capitalismo. Por meio disso, quero dizer que, mesmo na antimodernidade, pode-se reproduzir um modelo civilizatório moderno.

Um exemplo para sairmos da rede "Modernidade-Colonialidade". Consideremos o Estado Islâmico no Oriente Médio. Quando você observa suas abordagens, pode ver que elas são hipermodernas. Quando lê a imprensa eurocêntrica, tem-se a impressão de que essas abordagens correspondem a um projeto medieval, mas não: eles são hipermodernos em suas práticas e concepções. Na tradição muçulmana a noção de califado nunca foi equivalente a de estado-nação. O estado-nação é a ficção sobre a correspondência individual entre a identidade do estado e a identidade da população que reside em seu território, uma das tantas quimeras políticas da modernidade. O estado-nação faz parte da lógica civilizadora da modernidade. Atualmente, há um movimento islâmico que adota o conceito de califado, que sempre foi uma forma de autoridade política multicultural que nunca teve a pretensão de corresponder entre a identidade do estado e a identidade da população - e coloniza-o como equivalente ao conceito de estado-nação. Isso nunca existiu em nenhum califado da civilização muçulmana. Pelo contrário, nos califados sempre houve uma heterogeneidade de formas culturais, de identidades e espiritualidade, sempre houve respeito pelas minorias; mas agora temos um movimento como o Estado Islâmico que adota a ideia de califado e coloniza-o dentro da lógica moderna de estadonação. Lembre-se que o lema da conquista da Andaluzia era "converta-se ao cristianismo ou morra". No século XXI: “democratize-se ou morra". No século XX: “desenvolvase ou morra". Essas práticas seguem as mesmas lógicas de domínio e exterminação de povos, a incapacidade de negociar as diferenças e a imposição de uma visão sobre as demais. A do Estado Islâmico, por sua vez, é "Wahabize-se ou morra". Nesse contexto eles utilizam as principais estruturas da modernidade, mas agora recicladas como algo autenticamente islâmico, e aí estão as principais armadilhas que parte do decolonial possui. A atitude decolonial não se baseia somente em criticar as estruturas exteriores do sistema, porque essas estruturas, vale a pena lembrar, estão dentro de todos nós e formam parte de nossa subjetividade. Grande parte da dificuldade de descolonização deve-se a essa dimensão interna colonial em nossa maneira de ser e estar no mundo. É a dificuldade de descolonizar nosso interior e não somente a parte externa.

A meu ver, em nome de algo "autenticamente antiocidental" podemos acabar reproduzindo o ocidentalismo. Chamo a atenção para isso porque não é uma tarefa 
fácil, requer ir mais a fundo e ter certos cuidados para saber em que consiste a lógica civilizatória do mundo moderno, ou seja, o que é a modernidade e do que se trata. Se é um projeto civilizatório de morte, como nos alertam os pesquisadores e pesquisadoras indígenas ao redor do mundo, temos então que examinar com cuidado todas suas facetas e questionar: de que maneira operam essas lógicas modernas? Caso contrário, podemos cair na farsa de acreditar que, porque abraçamos uma suposta epistemologia exterior ao ocidente, estamos fora dele. Entretanto, o que acaba sendo feito é a reversão dos binarismos do ocidentalismo e a reprodução das lógicas civilizadoras da modernidade através de uma suposta autenticidade exterior. Daí a importância de identificar com cuidado as diferentes manifestações da modernidade e entender como operam e em que consistem. Pois, querendo ou não, podemos defender o autenticamente indigenista ou africano, ou o que quer que seja, enquanto reproduzimos ingenuamente o mundo contra o qual estamos lutando. Em suma, essa problematização não procura somente descolonizar a colonialidade do poder, mas também a do saber, do ser, e a maneira como nos relacionamos com outras formas de vida não humanas. Tudo isso está interligado sem possibilidade de separação: é assim que a modernidade funciona, e por isso temos que atacá-la simultaneamente em diferentes situações.

Para concluir, gostaria de acrescentar que não se trata de romper com as estruturas da modernidade da noite para o dia, isso é impossível. Faço esses esclarecimentos porque existem muitas leituras anarquistas que pretendem acabar com a modernidade de forma automática. Esse é um processo de longa duração. Enrique Dussel fala de "transmodernidade" enquanto formação de uma nova civilização, pois a civilização ocidental é aquela em que só existe um modelo de mundo possível. Portanto, a questão é como passamos de uma civilização que elege apenas uma forma de mundo como possível e as demais como impossíveis, para uma civilização que faça com que os outros mundos sejam possíveis e esse que estamos torne-se impossível. Essa transição para a geração de uma nova civilização, além da modernidade, não é uma coisa de dez ou quinze anos, é um processo que levará séculos. Essa mesma modernidade levou séculos para formarse e tomar proporções mundiais; portanto, se demoraremos séculos para concluir essa transformação, devemos nos perguntar seriamente quais são as tarefas atuais que nos ajudarão a construir essa "outra" realidade possível. Isso significa que temos que levar em conta todas as estruturas de poder existentes, para, em seguida, avaliar como mudamos daqui para outro mundo possível livre de toda forma de subjugação. Não podemos Revista X, v. 16, n. 1, p. 6-23, 2021. 
acabar automaticamente com as estruturas de poder como o estado moderno, entretanto podemos pensar politicamente sobre como faremos para descolonizar esse estado, como faremos para criar outro tipo de autoridade política que vá além do consenso da lógica liberal. É uma questão complexa, é um processo árduo transformar o "senso comum" que a modernidade produz.

E isso, a propósito, não quer dizer que deixemos de nos mobilizar politicamente devido ao fato de que a modernidade é um projeto civilizatório difícil de desmantelar. Existem muitas atitudes políticas que podemos tomar desde já para construir esse outro mundo possível - temos o exemplo, não somente de movimentos sociais, mas de uma esquerda latino-americana que, mesmo com todos seus problemas (porque é uma esquerda que reproduz as lógicas de dominação da modernidade), apresenta diversos obstáculos ao império. E é essa a razão pela qual devemos assumir uma posição política decidida frente aos ataques do império. Não podemos nos tornar cúmplices do império, temos que criticar, mas ao mesmo tempo temos a obrigação de desenvolver uma crítica que contribua para avançar além das lógicas civilizatórias modernas que a esquerda ocidentalizada reproduz. É um grande desafio para o qual não é possível encontrar todas as respostas apenas em um breve ensaio.

\section{REFERÊNCIAS}

DAVIS, Angela. Mulheres, raça e classe. Tradução de Heici Regina Candiani. São Paulo: Boitempo, 2016.

DUSSEL, Enrique. Postmodernidad y transmodernidad. Puebla: Universidad Iberoamericana Plantel Laguna, 1999.

FANON, Frantz. Os Condenados da Terra. $2^{\mathrm{a}}$ ed. Rio de Janeiro: Civilização Brasileira, 1979.

GONZÁLEZ, Pablo Casanova. Colonialismo interno (uma redefinição). In: BORON, Atilio; AMADEO, Javier; GONZÁLEZ, Sabrina (Org.) A teoria Marxista hoje. Problemas e perspectivas. 2007. p. 431-458. Disponível em: http://bibliotecavirtual.clacso.org.ar/ clacso/formacion-virtual/20100715073000/boron.pdf. Acesso em: 03 mai. 2020.

GROSFOGUEL, Ramón et al. "La izquierda despolarizada: del monólogo de Próspero al diálogo com Calibán”. Disponível em: https://drive.google.com/file/d/0B6g8xuEX_ KoJZ0R3bzdMb0NINUk/view. Acesso em: jun. 2018. 
GROSFOGUEL, Ramón. 'Del 'extractivismo económico' al 'extractivismo epistémico' y 'extractivismo ontológico': una forma destructiva de conocer, ser y estar en el mundo". Tábula Rasa, n. 24, p. 123-143, 2016.

GROSFOGUEL, Ramón. 'Del ‘extractivismo económico’ al ‘extractivismo epistémico’ y 'extractivismo ontológico". Revista Internacional de Comunicación y Desarrollo, n. 4, p. 33-45, 2015.

GROSFOGUEL, Ramón. "Los dilemas de los estúdios étnicos estadounidenses: multiculturalismo identitario, colonización disciplinaria y espitemologías decoloniales". Universitas Humanística, n. 63, p. 35-47, 2007.

MIGNOLO, Walter. Capitalismo y geopolítica del conocimiento: el eurocentrismo y la filosofía de la liberación en el debate intelectual contemporáneo. Buenos Aires: Ediciones del Signo, 2014.

OYĖWUMÍ, Oyèrónké. La invención de las mujeres. Una perspectiva africana sobre los discursos occidentales de género. Bogotá: Ediciones en la frontera, 2017.

QUIJANO, Aníbal et al. "Llamado internacional urgente a detener la escalada de violencia en Venezuela. Mirar a Venezuela, más allá de la polarización”. Disponível em: http:// llamadointernacionalvenezuela.blogspot.de/2017/05/1lamado-internacional-urgentedetener_30.html. Acesso em: dez. 2017.

ROBINSON, Cedric. Black Marxism: The Making of the Black Radical Tradition. Carolina do Norte: University of North Carolina Press, 2000.

SANTOS, Boaventura de Souza. Democracia de alta intensidad: apuntes para democratizar la democracia. La Paz: Unidad de Análisis y Investigación del Área de Educación, 2004.

WALLERSTEIN, Immanuel. El capitalismo histórico. Madrid: Siglo Veintiuno editores, 2003.

WALLERSTEIN, Immanuel; ARRIGHI, Giovanni; HOPKINS, Terence. Movimientos antisistémicos. Madrid: Editorial Akal, 1999. 